\title{
Methodological Principles of Assessing the Level of Technology Readiness for Transfer on the Basis of the Theory of Reliability of Hierarchically Branched Systems
}

\author{
Vasyl Kozyk ${ }^{1}$, Oleksandra Mrykhina ${ }^{1 *}$, Igor Novakivskyi ${ }^{1}$ and Orest Koleshchuk ${ }^{1}$ \\ ${ }^{1}$ Lviv Polytechnic National University, Institute of Economics and Management, Bandery Str., 12, \\ 79013 Lviv, Ukraine
}

\begin{abstract}
The methodological principles of assessing the level of technology readiness for transfer from universities to the business environment are developed, in particular: a model and a set of tools for evaluating the readiness of technologies for transfer, a method for evaluating the level of technology readiness for transfer on the basis of the theory of reliability of hierarchically branched systems. The development is aimed at shortening the term of technology withdrawal into the market and its distribution on it; increasing the efficiency of technology commercialization; to become the basis for substantiating the investment indicators of technology projects. Methodical development was tested on the example of the technology of the means of personal passive optically stimulated luminescence (OSL) dosimetry of ionizing radiation (IR). The methodological principles for assessing the level of technology readiness for transfer are intended for use by specialists of technology transfer centers at higher education institutions or similar entities, auditors, technology appraisers, institutional level managers in the field of innovation development, etc.
\end{abstract}

\section{Introduction}

The model of open innovation has updated the need to review traditional approaches to innovation in the countries of the world. Universities are one of the main participants in the modern world ecosystem of innovation, which, besides educational and research roles, accumulate entrepreneurial activity, which is realized on the principles of technology transfer. The rethinking of society of the importance of universities as technology generators has focused attention on the problem of increasing the efficiency of their transfer to production. This necessitates the development of new approaches and tools for transferring technology from universities to the business environment.

\footnotetext{
${ }^{*}$ Corresponding author: oleksandramrykhina@gmail.com
} 
Over the past decades, many technology scientists and practitioners have been discussing technology transfer issues, in particular [1-10]. Despite the significant number of developments in technology transfer pricing, there are no developments that would make it possible to set the level of technology readiness for the transfer and also indicate possible scenarios of technology development after its market launch. The unresolved problem of assessing the readiness of technologies for transfer in a methodical plan makes it impossible to substantiate further actions with these technologies.

Such a situation hinders the strategic development of universities in the system of interaction "University - Governmental Authority - Business". At the time, the development of methodological principles for assessing the readiness of technologies for transfer, which would facilitate the efficient and effective transfer of technologies from universities to the business environment on the one hand, on the other - would form a culture of university entrepreneurship.

\section{Formation of a three-level hierarchical model of technology transfer assessment}

Assessing the readiness of technologies for the purpose of their transfer often requires an analysis of interdisciplinary aspects, the consideration of components that significantly vary in meaning content and so on. This requires aggregation of the indicators included in the model. The international and domestic experience in evaluating technologies from the point of view of their transfer suggests that such an assessment should be based on an integrated approach that takes into account the value and cost parameters of the technology.

Based on the conducted researches of international practice on assessing the readiness of technologies for transfer from universities to the business environment, studying the national specifics of scientific and technical activities of universities, a model for evaluating the level of readiness of technologies for transfer is proposed. The model is based on an integrated approach, consisting of five units of evaluation: the consumer value of technology; the competitiveness of technology; technological readiness of technology; technology cost; the riskiness of the technology.

The preparation of technology for transfer is expedient to consider in the context of three conceptual levels that explain the content of this or that stage of technology readiness:

- I level: determination of technology transferability;

- II level: substantiation of the possibilities for transfer of the selected technology;

- III level: the choice of the technology transfer option.

\section{Expert evaluation of parameters of the three-level hierarchical model of technology transfer estimation}

The proposed model integrally covers five main blocks, each of which contains nine stages of technology readiness for the transfer. The need for the allocation of these units is confirmed by the statistical research of technological institutions of higher education of Ukraine during 2018-2019. The purpose of this statistical study was to determine the problems of technology transfer in the identified field in domestic developers. The research was conducted on the basis of a questionnaire.

In the process of statistical analysis, the opinion of representatives of research departments, marketing services of the Lviv Polytechnic National University and enterprises-manufacturers, as well as representatives of the consumer segment was studied. The essence of the survey was to assess the likelihood of a technology transfer ready according to the specified evaluation steps for the indicated blocks per 100 ball scale, 
which represents the probability scale from 0 to 1 . The information base of the conducted research consists of the results of a survey of 21 participants in the development of technologies (Higher Education Institution) of various types of economic activity regarding the effectiveness of selecting and evaluating technologies at one or another stage of the model blocks.

It should be noted that the survey conducted is representative, since in Ukraine there are 277 institutions of higher education conducting scientific and technical activities. In all calculations the level of significance $\alpha=0.05$; error is 1 point; the variance does not exceed 4. In such conditions, the required sample size is $n=12.06$ representatives of the business entities involved in the survey.

We will conduct the initial study of the obtained sample by calculating relevant indicators. The value of the quantilet $t_{t a b l}$ according to the Student's table for the technology transfer assessment units was $t_{t a b l}(n-1, \alpha / 2)=t_{\text {tabl }}(48 ; 0.025)=2.01063476$.

It is worth mentioning that the confidence intervals for all units of assessment of the availability of technologies for the transfer are largely high and close to each other. The largest spread has shown the assessment of the technology cost-absorption unit. This is due to the fact that subjects of the survey have different views on the importance of this or that technology transfer assessment unit.

The assertion that estimates for the evaluation units of this evaluation model were not accidental was checked on the hypothesis of the homogeneity of the mean values of the sampled samples obtained for each pair of blocks of the technology transfer readiness assessment model. Without reservations, we can assume that the sample mean has a normal distribution. In order to prove the homogeneity of technology transfer assessment units, it is enough to prove that a zero hypothesis is satisfied $H_{0}: \bar{Y}_{i}=\bar{Y}_{j}$. The competing hypothesis has the form $H_{1}: \bar{Y}_{i} \neq \bar{Y}_{j}$, so the critical area is two-sided. In this case, a random variable can be used to estimate the hypothesis:

$$
Z\left(Y_{i}, Y_{j}\right)=\left|\bar{Y}_{i}-\bar{Y}_{j}\right| / \sqrt{\frac{D\left(Y_{i}\right)}{n_{Y_{i}}}+\frac{D\left(Y_{j}\right)}{n_{Y_{j}}}} .
$$

If, then $Z\left(Y_{i}, Y_{j}\right)<Z_{\text {crit }}$, the null hypothesis is accepted; otherwise, it is rejected, where the critical value is $Z_{\text {crit }}=1.645$ from the equation $W\left(Z_{\text {crit }}\right)=(1-2 \alpha) / 2=0.495$, where is $W\left(Z_{\text {crit }}\right)$ the Laplace function. The calculated values $Z\left(Y_{i}, Y_{j}\right)$ of pair interactions between $i^{\text {th }}$ and $j^{\text {th }}$ technology transfer estimation blocks are given in Table 1.

Table 1. The calculated values of pair interactions are calculated $Z\left(Y_{i}, Y_{j}\right)$.

\begin{tabular}{|c|c|c|c|c|c|}
\hline$i$ & $\begin{array}{c}\text { Consumer value } \\
\text { of technology }\end{array}$ & $\begin{array}{c}\text { Competitivenes } \\
\text { s of technology }\end{array}$ & $\begin{array}{c}\text { Technological readiness } \\
\text { of technology }\end{array}$ & $\begin{array}{c}\text { The cost of } \\
\text { technology }\end{array}$ & $\begin{array}{c}\text { Risk of } \\
\text { technology }\end{array}$ \\
\hline $\begin{array}{c}\text { Consumer value } \\
\text { of Technology }\end{array}$ & 18.210 & 25.738 & 47.835 & 97.910 \\
\hline $\begin{array}{c}\text { Competitiveness } \\
\text { of technology }\end{array}$ & 18.210 & & 7.341 & 32.563 & 85.340 \\
\hline $\begin{array}{c}\text { Readiness of } \\
\text { technology }\end{array}$ & 25.738 & 7.341 & & 26.967 & 81.596 \\
\hline $\begin{array}{c}\text { The cost of } \\
\text { technology }\end{array}$ & 47.835 & 32.563 & 26.967 & & 49.006 \\
\hline
\end{tabular}




\begin{tabular}{|c|c|c|c|c|c|}
\hline $\begin{array}{c}\text { Risk of } \\
\text { technology }\end{array}$ & 97.910 & 85.340 & 81.596 & 49.006 & \\
\hline
\end{tabular}

As can be seen from Table 1, for all pairwise comparisons, there is an inequality $Z\left(Y_{i}, Y_{j}\right)>Z_{\text {crit }}$, which means a clear separation of the respondents with the role of these blocks of technology transfer assessment.

\section{Practical testing of the model}

For the practical implementation of the proposed model for evaluating the readiness of technologies for the transfer, a special toolkit has been developed, one of the methods of which is a method for evaluating technologies based on the theory of reliability of hierarchically branched systems.

From the point of view of the theory of reliability of hierarchically branched systems, it is expedient to decompose the proposed model for assessing the readiness of technologies for the transfer (hereinafter referred to as the model) to three levels:

- the zero level of the hierarchy $\left(P_{0}\right)$, where technology transfer centers (or other similar units of universities) receive technology and substantiate its transferability (reflecting a higher level of modeling);

- the first level of the hierarchy $\left(P_{1}\right)$, which specifies the possibilities for the transfer of the selected technology (contains the main blocks of the technology transfer assessment model);

- the second level of the hierarchy $\left(P_{2}\right)$, which is the multi-stage target assessment of the technology transfer.

In the given three-level hierarchical model on the branches $P_{0}-P_{1}$ and $P_{1}-P_{2}$ elements of the model are placed. At the highest level (roots) of the hierarchy there is a technology that is appreciated.

Given that the main five blocks of the evaluation model are placed on the first level of the hierarchically branched system, we will construct a generic function to determine the level of readiness of the technologies for the transfer. In the classical model, we assume that the evaluation blocks on the branches $P_{0}-P_{l}$ are homogeneous and symmetric. Under these assumptions, the creature function can be written as follows:

$$
S_{1}(z)_{\text {сим }}=P_{0}\left(P_{1} z+q_{1}\right)^{a_{1}}+q_{0},
$$

where $P_{0}, P_{1}$ - is the probability of passage of the zero stage and the first, respectively, levels of the model of evaluation of the readiness of technologies for transfer; $q_{0}, q_{1}$ - is the probability of non-passage of the phase of zero and the first, respectively, levels of the model of the evaluation of the readiness of the technologies for the transfer; ai is the number of branches at the $i^{\text {th }}$ level of assessment $\left(a_{l}=5\right), z$ - is an artificial auxiliary indicator, in partial cases it can be interpreted as an indicator of the relative term of technology withdrawal into the market $(0 \leq \mathrm{z} \leq 1)$. Note that for the evaluated technology, the probability of its successful conclusion is unconditional, that is $P_{0}=1$. Obviously, the probability of turning off the transfer is impossible, but because $q_{0}=0$.

The creature function (1) should be used when determining the level of readiness of technologies in the first level of the model on the branches $P_{0}-P_{1}$ also in the case of heterogeneous elements of the first level. Having made the corresponding mathematical transformations, by analogy obtained:

$$
S_{1}(z)=P_{0} \prod_{i=1}^{a_{1}}\left(P_{1 i} z+q_{i}\right)+q_{0},
$$

where $P_{1}-$ is the probability of passing the first stage, the level of the model for assessing the 
availability of technologies to the transfer by blocks: consumer value, competitiveness, technological readiness, cost and riskiness:

$$
\begin{gathered}
P_{1}(5)=P_{0} P_{11} P_{12} P_{13} P_{14} P_{15} ; P_{1}(4)=P_{0}\left(P_{12} P_{13} P_{14} P_{15} q_{1}+P_{11} P_{13} P_{14} P_{15} q_{2}+\right. \\
\left.P_{11} P_{12} P_{14} P_{15} q_{3}+P_{11} P_{12} P_{13} P_{15} q_{4}+P_{11} P_{12} P_{13} P_{14} q_{5}\right) ; \\
P_{1}(3)=P_{0}\left(P_{11} P_{12} P_{13} q_{4} q_{5}+P_{11} P_{12} P_{14} q_{3} q_{5}+P_{11} P_{13} P_{14} q_{2} q_{5}+P_{12} P_{13} P_{14} q_{1} q_{5}+\right. \\
P_{11} P_{12} P_{15} q_{3} q_{4}+P_{11} P_{13} P_{15} q_{2} q_{4}+P_{12} P_{13} P_{15} q_{1} q_{4}+P_{11} P_{14} P_{15} q_{2} q_{3}+P_{12} P_{14} P_{15} q_{1} q_{3}+ \\
\left.P_{13} P_{14} P_{15} q_{1} q_{2}\right) ; P_{1}(2)=P_{0}\left(P_{11} P_{12} q_{3} q_{4} q_{5}+P_{11} P_{13} q_{2} q_{4} q_{5}+P_{11} P_{14} q_{2} q_{3} q_{5}+\right. \\
P_{11} P_{15} q_{2} q_{3} q_{4}+P_{12} P_{13} q_{1} q_{4} q_{5}+P_{12} P_{14} q_{1} q_{3} q_{5}+P_{12} P_{15} q_{1} q_{3} q_{4}+P_{13} P_{14} q_{1} q_{2} q_{5}+ \\
\left.P_{13} P_{15} q_{1} q_{2} q_{4}+P_{14} P_{15} q_{1} q_{2} q_{3}\right) ; P_{1}(1)=P_{0}\left(P_{11} q_{2} q_{3} q_{4} q_{5}+P_{12} q_{1} q_{3} q_{4} q_{5}+\right. \\
\left.P_{13} q_{1} q_{2} q_{4} q_{5}+P_{14} q_{1} q_{2} q_{3} q_{5}+P_{15} q_{1} q_{2} q_{3} q_{4}\right) ; P_{1}(0)=P_{0} q_{1} q_{2} q_{3} q_{4} q_{5}+q_{0}
\end{gathered}
$$

According to the probability theory, the sum of probable states at each level of the hierarchical model should be equal to 1 . To do this, it is necessary to set the value of each of the elements (stages) on the branches $P_{0}-P_{l}$ so that they total 1 .

Accordingly, the mathematical expectation of meeting the requirements for estimating the number of output working elements in this system can be determined from the expression:

$$
M\left(x_{1}\right)=5 P_{1}(5)+4 P_{1}(4)+3 P_{1}(3)+2 P_{1}(2)+P_{1}(1)
$$

In assessing the transfer of technology of personal passive OSL dosimetry of IR, the given analysis shows the readiness indicators at the first level, that is, this technology is between the zero and the first levels of the hierarchical model of evaluation. In this case, the evaluation of each of the blocks of the hierarchical model is carried out, that is, they carry out work coordination of the transfer of technologies. By analogy, the process of technology evaluation is transferred to the next nine stages of the second level of the hierarchical model for evaluating the level of technology readiness for the transfer.

The proposed conceptual model for assessing the level of technology readiness for transfer is symmetric in its structure, branched to the second level $\left(P_{0}, P_{1}, P_{2}\right)$. Thus, the number of branches in the model is five on the first $\left(a_{1}=5\right)$ and nine on the second $\left(a_{2}=9\right)$ levels. The constructed branched three-level hierarchical model can be represented as a generalized creature function:

$$
S_{2}(z)=P_{0} \prod_{i=1}^{a_{1}}\left(P_{1 i} \prod_{j=1}^{a_{2}}\left(P_{2 j} z+q_{2 j}\right)+q_{1 i}\right)+q_{0}
$$

The method of determining mathematical expectation is calculated in accordance with the law of discrete distribution on the theory of probability:

$$
M\left(x_{2}\right)=\left.\frac{\partial S_{2}(z)}{\partial z}\right|_{z=1}
$$

In this work, the level of readiness of the technology for this model was calculated. It should be noted that due to the complexity of representing the formulas, the necessary calculations at the second level of the three-level hierarchical model for the technology of the means of personal passive OSL dosimetry of IR were conducted in the environment EXCEL. It is worth noting that in each individual case, the assessment of a particular stage is determined individually. Separate technologies do not require the obligatory passage of individual stages. In this case $P_{i j}=0$, since it does not affect the final result of the calculation.

\section{Conclusion}

The methodical principles of estimating the level of readiness of technologies for transfer were developed, in particular: 
1) a model for assessing the level of technology readiness for transfer based on five technology assessment units (consumer value, competitiveness, technological readiness, cost, risk), each of which consists of nine stages of readiness assessment, which determine three levels readiness of technology.

The proposed method of estimating the level of technology readiness for transfer on the basis of the theory of reliability of hierarchically branched systems is based on the development: an extensive creature function for a system of a conceptual model for assessing the level of technology readiness for the transfer; recursive expression for calculating the distribution of probabilities of the number of output working elements of the conceptual model of the evaluation of the level of readiness of the technology for the transfer; mathematical expectation of the number of output working elements of the conceptual model of the evaluation of the level of readiness of the technology for the transfer;

2) testing of the developed toolkit on the example of the technology of personal passive OSL dosimetry of IR showed the following result of $79.60 \%$ of the readiness of this technology to the transfer.

In general, application of the theory of reliability of hierarchically branched systems in the framework of the proposed model for assessing the level of readiness of the technology for transfer allows: to increase the accuracy of obtaining the indicator of readiness of technology for the transfer; on the basis of recurrent expressions, to determine the nature of the interaction of elements among themselves, on the basis of which to draw conclusions about the level of development of technology and features of both its evaluation and transfer.

\section{References}

1. J. Bercovitz, M. Feldman,. The Journal of Technology Transfer, 31, 1 (2006).

2. S. Bradley, C. Hayter, A. Link, Foundations and Trends in Entrepreneurship, 9(6) (2013).

3. Goldsmith Technology Commercialization Model. Nebraska Business Development Center. College of Business Administration (2018). Available at: https://www.unomaha.edu/nebraska-business-development-center/technologycommercialization/goldsmith-technology/index.php

4. S. Hess, R. Y. Siegwart. Business and Management Research, 2 (2013)

5. V. Kozyk, O. Mrykhina, O. Koleshchuk, T. Mirkunova, Technology audit and production reserves, $\mathbf{3 / 4}$ (41) (2018).

6. D. Ye. Marunchak, A. R. Sydor, Nadiinist rozghaluzhenykh system [Reliability of branched systems7, Lviv polytechnic publishing house (2007).

7. O. B. Mrykhina, Actual Problems of Economics, 8 (2014).

8. NASA Technology Readiness Level (2017). Available at: https://www.nasa.gov/directorates/heo/scan/engineering/technology/txt_accordion 1.html

9. I. I. Novakivskyi, Bulletin of the Lviv Polytechnic National University. Series: Problems of Economics and Management, 754, (2013)

10. D. S. Siegel, D. A.Waldman, L. E. Atwater, A. N. Link, Journal of Engineering and Technology Management, 21(1-2) (2004). 